\title{
PLEOMORPHIC ADENOMA OF THE NASAL SEPTUM
}

\author{
Sunil Kumar Saxena', S. Gopalakrishnan²
}

\begin{abstract}
Despite the common occurrence of pleomorphic adenoma of major salivary glands, intranasal pleomorphic adenoma are rare. We present a case of pleomorphic adenoma of the nasal septum along with a brief review of literature. The histological nature of this lesion in comparison to other salivary gland tumours and the importance of an accurate diagnosis has been stressed.
\end{abstract}

Key Words : Nasal septum; salivary gland neoplasms; Adenoma; Pleomorphic.

\section{INTRODUCTION}

Pleomorphic adenoma is the most common type of benign epithelial salivary tumour. It most frequently presents in the major salivary glands, however it can also occur in minor salivary glands. Only $10 \%$ of pleomorphic adenomas arise in minor salivary glands (Krolls and Hicks, 1973). The most common locations are the hard and soft palate and upper lip. Intranasal pleomorphic adenoma is extremely rare (Bergstrom and Biorkland, 1981). Among all reported cases of pleomorphic adenomas in the nasal cavity, $80 \%$ arose from the mucosa of cartilaginous or bony septum and only $20 \%$ originated from the lateral nasal wall (Compango and Wong, 1977).

Pleomorphic adenoma is seen as a slowly growing, painless firm mass which has a smooth surface. Clinically intranasal pleomorphic adenoma present with unilateral nasal obstruction, mass in the nasal cavity, intermittent nasal discharge and epistaxis. We present one such rare case of pleomorphic adenoma of the nasal septum.

\section{CASE REPORT}

A 30 years old female presented with left sided nasal obstruction and periodic epistaxis for the past 2 years. She did not give any history of headache, facial pain, changes in vision, loss of olfaction or weight loss.

Physical examination revealed a greyish white mass completely filling the left nasal cavity. On probing it was found to be firm and arising from the bony part of the nasal septum. The septum was deviated to the right side. The post-nasal space and palate were normal. There was no cervical lymphadenopathy, CT scan.showed a mass in the left nasal cavity abutting the nasal septum (Fig. 1). Biopsy of the mass suggested the diagnosis of pleomorphic adenoma. Excision of the mass down to and including the mucoperiosteum was done through the lateral rhinotomy

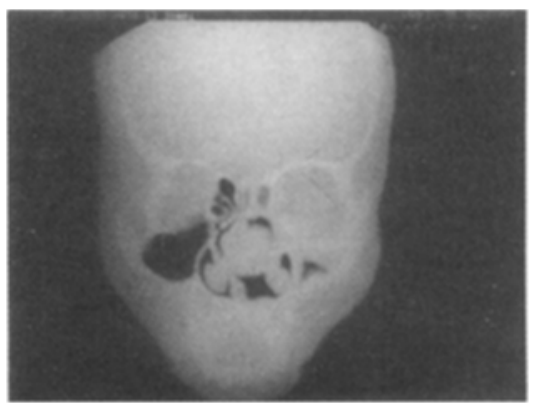

Fig. I : Coronal CT Scan showing mars abutting from the septum in lef nasal cavity

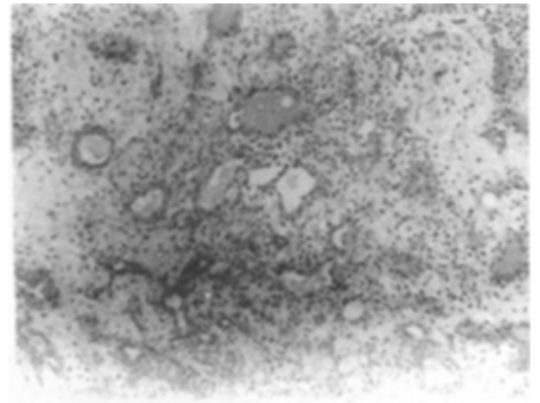

Fig. II : Histologic primary of Pl addiction.

approach. Histopathological examination of the excised mass confirmed the diagnosis with clear margins. The post-operative course was uneventful. She has been followed up for 12 months since treatment without any recurrence.

\section{DISCUSSION}

Histologic appearance of pleomorphic adenoma includes admixture of epithelial, myoepithelial and stromal components, including the presence of acini or tubules and a myxochondroid stroma; in a given tumour, the ratio of these components varies so that any one component may dominate the histologic picture (Fig. II). Intranasal pleomorphic adenoma is highly cellular (epithelial) and, in

'Associate Professor, 'Professor and Head, Department of Otorhinolaryngology and Head \& Neck Surgery, JIPMER, Pondicherry- 605006 
contrast with pleomorphic adenoma of major salivary glands, has little myxoid stroma (Compango and Wong, 1977). Nasal pleomorphic adenoma thus are frequently interpreted as more aggressive neoplasms on the basis of initial biopsy results. Many cases of misdiagnosis of pleomorphic adenoma of the nasal cavity such as squamous cell carcinoma, adenoid cystic carcinoma and adenocarcinoma are reported in the literature (Haberman and Stanley, 1989: Liao et al, 1993). Such misdiagnosis emphasizes the need to obtain a biopsy specimen sufficiently large and from tissue deep enough to include the sparse myxoid stroma, thus enabling the correct diagnosis of Pleomorphic adenoma to be made.

The treatment of choice for pleomorphic adenoma in the nasal cavity is local surgical excision with histologically clear margins (Suzuki et al, 1990). Various surgical approaches depend on size and location of the tumor in the nasal cavity. They include intranasal excision, facial degloving, and lateral rhinotomy. Incomplete excision results in recurrent tumor. Carcinoma arising in the pleomorphic adenoma of the nasal cavity has also been reported (Cho et al, 1995).

The above case illustrates that pleomorphic adenoma can be considered as a rare possibility in the differential diagnosis of nasal tumors and otolaryngologists must be aware of the difficulty of correctly diagnosing initial tissue biopsy specimen in order to guard against unnecessary radical surgery.

\section{REFERENCES}

1. Krolls SO. Hicks JL (1973) : Mixed turnour of lower lip. Oral Surg. Oral Med, Oral Pathol. 35, 212-7.

2. Bergstrom B. Biorkland A (1981) : Pleomorphic adenoma of the nasal septum : Report of two cases, J. Laryngol Otol. 95; 179-181.

3. Batsakis JB (1984): Tumor of the head and neck. $2^{\text {nd }}$ edition Baltimore, The Williams and Wilkins Co, pp. 76-99.

4. Compango J., Wong RT (1977) : Intranasal mixed turnours (pleomorphic adenoma) : A clinicopathologic study of 40 cases. American Journal of Clinical Pathology. 68; 213-218.

5. Been S. Liao, Raymond L, Hilsinger Jr., Edmund Chog (1993) : Septal pleomorphic adenoma masquerading as squamous cell carcinoma. ENT Journal 72; 781-783

6. Rex S. Haberman, Donald E. Stanley (1989) : Pleomorphic adenoma of the nasal septum. Otolaryngologic - Head and Neck Surgery. 100; 610-612.

7. Suzuki K. Moribe K, Baba S (1990) : A rare case of pleomorphic adenoma of the lateral wall of the nasal cavity with special reference of statistical observation of pleomorphic adenoma of the nasal cavity in Japan, Journal of the Oto-RhinoLaryngological Society of Japan. 93 (5); 740-745.

8. Cho KJ, EI-Naggar AK, Mahanupab P., Luna MA., Bastakis JG (1995): Carcinoma ex-pleomorphic adenoma of the nasal cavity a report of two cases. Journal of Laryngology and Otology $109 ;(7) ; 677-679$.

\section{Address for correspondence :}

Dr. Sunil Kumar Saxena

Associate Professor,

Department of Otorhinolaryngology

and Head \& Neck Surgery,

JIPMER, Pondicherry - 605006

\section{NASAL TOOTH}

\section{Des Raj Bhagat', Padam Singh ${ }^{2}$, Sunil Kotwal ${ }^{3}$, Ashok Sharma ${ }^{4}$, Jyoti Mahotra ${ }^{5}$}

\section{INTRODUCTION}

Ecotopic and supernumerary teeth occur at a wide varìty of sites, The reported sites include the orbit, palate, maxillary antrum, mandibular condyle, coronoid process, nose or through the skin. Tooth eruption in the nasal cavity is rare and easily overlooked. Ectopic teeth may be permanent or deciduous and the permanent ones are usually incisors, but can be canines, pre-molars or molars. In deciduous dentition, the supernumerary tooth is usually a maxillary lateral incisor (Shafer et al, 1974). Approximately, $90 \%$ of all supernumerary teeth occur in the maxilla. Supernumerary teeth in the deciduous dentition are much less common than in the premanent teeth.

A supernumerary tooth originates from the third tooth bud which arises from the dental lamina near the permanent tooth bud. It may or may not resemble the parent tooth either in shape or size and is usually found in greatest frequency in certain sites. It is not unusual for the condition to be bilateral. Supernumerary teeth are much more common than supplemental teeth. The supernumerary tooth found in the incisor region is known as the

'P.G. Student, ${ }^{2}$ Lecturer, ${ }^{3}$ Associate Professor, ${ }^{4}$ Senior Resident, Department of ENT, SMGS Hospital, Govt. Medical College, Jammu ${ }^{5}$ Dental Surgeon, Jammu city. 